Abstract EPV135/\#596 Table 1 Clinicopathological features according to MMR expression

\begin{tabular}{|c|c|c|c|c|}
\hline & & PMMR & dMMR & p-value \\
\hline \multicolumn{2}{|c|}{ Average age at diagnosis (min-max) } & $62.5(31-85)$ & $62.7(36.2-84.5)$ & 0.976 \\
\hline \multicolumn{2}{|c|}{ Average body mass index (min-max) } & $31.2(16.4-54.0)$ & $30.9(19.3-47.6)$ & 0.601 \\
\hline \multirow{2}{*}{ Menopausal status } & Post-menopause & $278(91.1 \%)$ & $127(84.6 \%)$ & \multirow{2}{*}{0.121} \\
\hline & Pre-menopause & $27(8.9 \%)$ & $20(13.6 \%)$ & \\
\hline \multirow{4}{*}{ Ethnicity } & White & $217(76.7 \%)$ & $110(79.1 \%)$ & \multirow{4}{*}{0.705} \\
\hline & Black & $14(4.9 \%)$ & $9(6.5 \%)$ & \\
\hline & Brown & $43(15.2 \%)$ & $16(11.5 \%)$ & \\
\hline & Asian & $9(3.2 \%)$ & $4(2.9 \%)$ & \\
\hline \multirow{2}{*}{ Family cancer history } & Negative & $187(71.6 \%)$ & $82(65.1 \%)$ & \multirow{2}{*}{0.188} \\
\hline & Positive & $74(28.4 \%)$ & $44(34.9 \%)$ & \\
\hline \multirow{2}{*}{ Personal cancer history } & Negative & $248(82.9 \%)$ & $119(81.0 \%)$ & \multirow{2}{*}{0.605} \\
\hline & Positive & $51(17.1 \%)$ & $28(19.0 \%)$ & \\
\hline \multirow{2}{*}{ Hypertension } & Absent & $119(39.4 \%)$ & $57(39.3 \%)$ & \multirow{2}{*}{0.985} \\
\hline & Present & $183(60.6 \%)$ & $88(60.7 \%)$ & \\
\hline \multirow{2}{*}{ Diabetes } & Absent & $220(72.8 \%)$ & $108(74.5 \%)$ & \multirow{2}{*}{0.714} \\
\hline & Present & $82(27.2 \%)$ & $37(25.5 \%)$ & \\
\hline \multirow{2}{*}{ Tumor histological type } & Endometrioid & $234(77.7 \%)$ & $125(85.0 \%)$ & \multirow{2}{*}{0.069} \\
\hline & Non-endometrioid & $67(22.3 \%)$ & $22(15.0 \%)$ & \\
\hline \multirow{2}{*}{ Tumor histological grade } & Low grade & $211(69.4 \%)$ & $102(68.9 \%)$ & \multirow{2}{*}{0.916} \\
\hline & High grade & $93(30.6 \%)$ & $46(31.1 \%)$ & \\
\hline \multirow{2}{*}{$\begin{array}{l}\text { Lymphvascular space } \\
\text { invasion }\end{array}$} & Absent & $237(79.3 \%)$ & $95(64.6 \%)$ & \multirow{2}{*}{0.001} \\
\hline & Present & $62(20.7 \%)$ & $52(35.4 \%)$ & \\
\hline \multirow{2}{*}{$\begin{array}{l}\text { Myometrial tumoral } \\
\text { invasion }\end{array}$} & $\begin{array}{l}<50 \% \text { of myometrial } \\
\text { thickness }\end{array}$ & $167(54.8 \%)$ & $67(45.6 \%)$ & \multirow{2}{*}{0.067} \\
\hline & $\begin{array}{l}250 \% \text { of myometrial } \\
\text { thickness }\end{array}$ & $138(45.2 \%)$ & $80(54.4 \%)$ & \\
\hline \multirow{4}{*}{ AGO staging } & 1 & $184(60.3 \%)$ & $84(56.8 \%)$ & \multirow{4}{*}{0.306} \\
\hline & "I & $30(9.8 \%)$ & $9(6.1 \%)$ & \\
\hline & III & $69(22.6 \%)$ & $43(29.1 \%)$ & \\
\hline & IV & $22(7.2 \%)$ & $12(8.1 \%)$ & \\
\hline \multirow{2}{*}{$\begin{array}{l}\text { p53 } \\
\text { immunohistochemistry } \\
\text { staining }\end{array}$} & Wild type & $181(74.8 \%)$ & $113(89.7 \%)$ & \multirow[b]{2}{*}{0.001} \\
\hline & Aberrant & $61(25.2 \%)$ & $13(10.3 \%)$ & \\
\hline \multirow{2}{*}{ Cancer recurrence } & Absent & $247(86.4 \%)$ & $108(83.1 \%)$ & \multirow{2}{*}{0.380} \\
\hline & Present & $39(13.6 \%)$ & $22(16.9 \%)$ & \\
\hline & Alive & $278(91.1 \%)$ & $120(81.1 \%)$ & \\
\hline & Death by cancer & $17(5.6 \%)$ & $17(11.5 \%)$ & \\
\hline Sunvival & Death by other causes & $10(3.3 \%)$ & $8(5.4 \%)$ & 0.004 \\
\hline & $\begin{array}{l}\text { Death of unknown } \\
\text { cause }\end{array}$ & 0 & $3(2.0 \%)$ & \\
\hline
\end{tabular}

pMMR: proficient mismatch repair (enzymes expressed)

dMMR: deficient mismatch repair (enzymes not expressed)

more prevalent in the pMMR group. Mortality was significantly higher in the dMMR group.

\section{EPV136/\#605 METFORMIN USE AMONG DIABETIC WOMEN AND ENDOMETRIAL CANCER SURVIVAL: AN ISRAELI GYNECOLOGIC ONCOLOGY GROUP STUDY}

${ }^{1} \mathrm{~B}$ Brandt, ${ }^{2} \mathrm{~T}$ Perri, ${ }^{3} \mathrm{~L}$ Helpman, ${ }^{4} \mathrm{R}$ Eitan, ${ }^{5} \mathrm{Z}$ Vaknin, ${ }^{6} \mathrm{O}$ Lavie, ${ }^{7} \mathrm{~A}$ Ben Arie, ${ }^{8} \mathrm{~A}$ Amit, ${ }^{9} \mathrm{~T}$ Levy, ${ }^{10} \mathrm{~A}$ Namazov, ${ }^{11}$ I Ben Shachar, ${ }^{12}$ I Atlas, ${ }^{13}$ I Bruchim, ${ }^{1} \mathrm{~L}$ Kogan*, ${ }^{10} \mathrm{O}$ Gemer. ${ }^{1}$ Hadassah, Gynecologic Oncology, Jerusalem, Israel; ${ }^{2}$ Hadassah Medical Center, Gynecologic Oncology, Jerusalem, Israel; ${ }^{3}$ Sheba medical center, Gynecologic Oncology, Ramat Gan, Israel; ${ }^{4}$ Rabin Medical Center, Gynecology, Petah Tikva, Israel; ${ }^{5}$ Assaf Haroffe Medical Center, Sackler School of Medicine, Gynecology, Zrifin, Israel; ${ }^{6}$ Carmel Medical Center, Obstetrics and Gynecology, Haifa, Israel; '72. Kaplan Medical Center, Hebrew University, Gynecology, Rehovot, Israel; ${ }^{8}$ Rambam, Gymecologic Oncology, Haifa, Israel; ${ }^{9}$ Wolfson Medical Center, Holon, Sackler Faculty of Medicine, Tel Aviv University, Gynecology, Tel Aviv, Israel; ${ }^{10}$ Barzilai Medical Center, Gynecology, Ashkelon, Israel; ${ }^{11} \mathrm{ZlV}$, Gynecologic Oncology, Zefat, Israel; ${ }^{12}$ Poriah, Gynecologic Oncology, Tiberia, Israel; ${ }^{13} \mathrm{Hilll}$ l Yafe, Gynecology, Hadera, Israel

\subsection{6/ijgc-2021-IGCS.206}

Objectives Diabetes mellitus is a risk factor for the development of endometrial hyperplasia and endometrial carcinoma (EC). We aimed to evaluate the association between metformin use and oncologic outcome in diabetic women with EC.

Methods A retrospective multi-center cohort study of diabetic women with EC treated in nine gynecologic oncology centers between 2000-2014. Univariate, Kaplan-Meier survival and Cox proportional hazard model analyses were performed to compare survival outcomes between women treated with metformin and those who were not.
Results A total of 577 diabetic women with EC were included, $330(57.2 \%)$ were treated with metformin and 247 were not. There was no difference between the groups in terms of age, hypertension, statin use, hormonal replacement therapy use, disease stage, grade, lymphovascular space invasion (LVSI) or median follow up time. Women treated with metformin were more likely to have positive abdominal fluid cytology and be operated by minimally invasive route (Odds Ratio [95\% Confidence Interval]: 2.8 [1.1-7.2] vs.1.6 [1.12.3], respectively). Median follow up was 53 months (interquartile range 20-91). Recurrence rate did not differ between study groups $(p=0.267)$. Cox proportional hazards model adjusted for age, disease stage, grade, LVSI, radiation therapy and chemotherapy, demonstrated comparable progression free survival and overall survival between diabetics who used metformin versus those who did not $(p=0.486, p=0.194$, respectively).

Conclusions Metformin use did not influence prognosis in diabetic women with EC. Large prospective studies to elucidate the association of metformin and oncological outcomes in diabetic subgroups of women with EC are of need.

\section{EPV137/\#607 EARLY SURGICAL OUTCOMES OF ROBOTIC HYSTERECTOMY AND SENTINEL LYMPH NODE BIOPSY USING INDOCYANINE GREEN (ICG)}

${ }^{1} \mathrm{C}$ lavazzo*, ${ }^{2} \mathrm{~A}$ Fotiou, ${ }^{1} \mathrm{~K}$ Kokkali, 'E Tepetzikiotis, 'S Lekka, ${ }^{1} \mathrm{D}$ Giannoulopoulos, ${ }^{1} \mathrm{G}$ Vorgias. 'Metaxa Memorial Cancer Hospital, Gynaecology Department, Piraeus, Greece; ${ }^{2}$ Metaxa Memorial Cancer Hospital, Gynaecological Oncology Department, Piraeus, Greece

10.1136/ijgc-2021-IGCS.207

Objectives Robotic hysterectomy and sentinel lymph node biopsy (SLNB) using Indocyanine green is an effective and safe alternative treatment for patients with endometrial cancer. Methods A single-institutional retrospective study was performed including all patients with intermediate-risk endometrial cancer who underwent robotic hysterectomy plus SLNB using ICG between January 2020 and April 2021. Surgical outcomes of these patients regarding lymphoedema and lymphocele formation were compared in a retrospective manner with outcomes of endometrial cancer patient that underwent abdominal hysterectomy and complete pelvic lymph node dissection.

Results In total from January 2020 until April 2021, 15 patients were surgically treated for intermediate endometrial cancer with robotic hysterectomy and SLNB using ICG. Their outcomes were compared with those who underwent abdominal hysterectomy plus pelvic lymph node dissection for endometrial cancer (30 patients). Regarding oncological outcome, 8 out of 15 patients of robotic group were treated for endometrioid endometrial cancer stage IB low grade without LVSI, while the rest of them had endometrioid endometrial cancer stage IA high grade. None of the included patients had metastases to the sentinel lymph node. Regarding the complications, none of the robotic group patients suffered from lymphoedema or lymphocele formation, while in abdominal group 1 out of 30 suffered from lymphoedema and 5 from lymphocele formation.

Conclusions Although our small experience, according to our results robotic hysterectomy in combination with SLNB is a feasible treatment that can be used in treatment of patients with intermediate endometrial cancer with same or even better long term results regarding lymphatic drainage. 